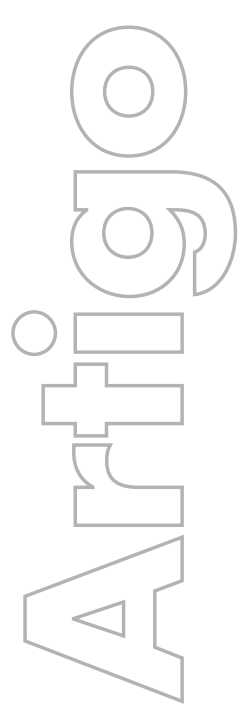

revista

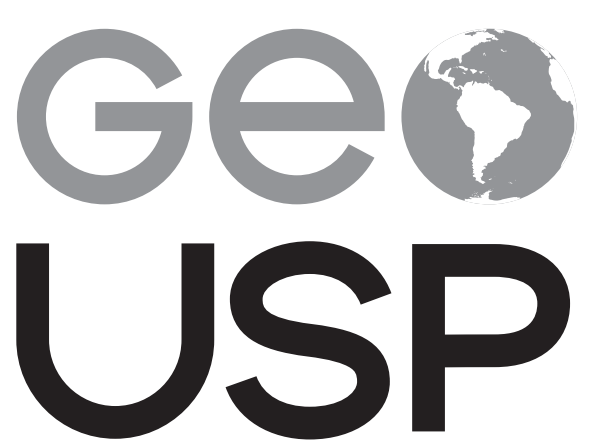

espaço e tempo

Volume $22 \cdot n^{\circ} 1(2018)$
Território, sertão e ciência: expedições civilizatórias e geografia no Brasil (1900-1930)

Carlo Eugênio Nogueira $\mathrm{CCHN} / \mathrm{UFES}$

p. $043-060$

Como citar este artigo:

NOGUEIRA, C. E. Território, sertão e ciência: expedições civilizatórias e geografia no Brasil (1900-1930). Geousp Espaço e Tempo (Online), v. 22, n. 1, p. 043-060, mês. 2018. ISSN 2179-0892.

Disponível em: <http://www.revistas.usp.br/geousp/article/ view/122319>. doi: http://dx.doi.org/10.11606/issn.2179-0892. geousp.2018.122319.

\section{(c) ()}

Este artigo está licenciado sob a Creative Commons Attribution 4.0 License. 


\title{
Território, sertão e ciência: expedições civilizatórias e geografia no Brasil (1900-1930)
}

\section{Resumo}

Tomando como pano de fundo o processo de formação territorial do país, o objetivo deste artigo é apreciar a relação entre a trajetória de consolidação da geografia como campo disciplinar e as imagens e concepções de base espacial presentes nos debates sobre a questão nacional no pensamento político-social do início do século XX. Especificamente, busca-se problematizar o ambiente intelectual onde se organizaram algumas expedições que perscrutaram o antigo território de Mato Grosso, sobretudo no que tange à conformação das noções de sertão e espaço vazio, associadas recorrentemente ao território mato-grossense, uma vez que, funcionando como ideologia geográfica, tais noções poderiam ser operacionalizadas para justificar e legitimar as políticas territoriais oficiais de colonização e povoamento que o integrariam ao resto do país.

Palavras-chave: História da geografia. Formação territorial. Sertão. Comissão Rondon.

\section{Territory, hinterland and science: civilizing expeditions and Geography in Brazil (1900-1930)}

\begin{abstract}
Based upon the analysis of the process of territorial formation in Brazil, this paper aims to assess the relationship between the consolidation of Geography as a disciplinary field and the construction of spatial images and concepts in the debates about the national question carried out in Brazilian political and social thought in early twentieth century. More specifically, this work seeks to examine the intellectual environment that prompted the expeditions to the ancient Mato Grosso territory, above all the notions of sertão and empty space, since these spatial concepts, working as geographic ideologies, could be used to legitimate and justify the relevance of official territorial policy regarding the settlement and integration of Mato Grosso to the bulk of Brazilian territory.
\end{abstract}

Keywords: History of Geography. Territorial formation. Sertão. Rondon Commission. 


\section{Introdução}

A preocupação com o estudo da formação territorial não é dos temas que se pode considerar de interesse recente dentro da geografia. Ao contrário, a descrição das etapas de construção dos limites políticos desenhados entre entes juridicamente reconhecidos é um dos problemas mais tradicionais postos por esse campo disciplinar, sendo até mesmo possível aproximar certos registros e autores de um discurso de celebração acrítica do Estado-nação (Martin, 1993; Newman, 2003). Entretanto, a visão de que o movimento da sociedade expressa uma dimensão geográfica da história humana, compreendida como um processo de reiterada antropomorfização da superfície terrestre, coloca a discussão a respeito do território em outros termos, pois assume que: "o processo de formação territorial é a manifestação empírica da valorização do espaço, da mesma maneira que a formação econômico-social expressa o modo de produção numa situação singular" (Moraes, 2014, p. 23).

Partindo desses princípios, propõe-se aqui apreciar o processo brasileiro de formação territorial a partir da análise pormenorizada da história de apropriação e uso de uma sua porção singular, o estado de Mato Grosso. Ao fazê-lo, pretende-se aprofundar o debate acerca da construção da territorialidade estatal no Brasil, revelando a dimensão espacial do movimento de construção social de um âmbito delimitado de exercício do poder (Sack, 1986; Taylor, 1994). Nesse enquadramento, a formação territorial surge simultaneamente como projeto de ocupação material e legitimação simbólica do avanço de uma sociedade sobre porções da superfície terrestre, sendo o território considerado realidade objetiva situada espacial e temporalmente (Moraes, 2000; Santos, 1997).

Em verdade, um dos pontos fundamentais cotejados neste texto é a conexão existente entre o processo de produção do espaço pela reiterada incorporação de valor ao solo e a posterior apropriação desse espaço socialmente produzido. Sendo assim, articula-se o entendimento da geografia como materialidade construída socialmente por grupos que conferem, a cada momento histórico, conteúdos distintos aos lugares (Santos, 2002), com sua definição como um discurso sistematizado sobre o espaço, isto é, uma representação referida genericamente à superfície terrestre que pode vir a participar do processo de produção da realidade que descreve (Bourdieu, 1989; Moraes, 1988; Ortiz, 2003).

De fato, diversos autores sublinham a importância das categorias espaciais na consolidação dos Estados nacionais, destacando-se como uma característica ímpar do caso brasileiro o papel ocupado pelas representações geográficas do país no processo de constituição da identidade nacional (Maia, 2008). Efetivamente, pode-se apontar a constituição de uma tradição dentro do pensamento político-social que considera certos atributos naturais do território como a matriz fundamental na construção da identidade brasileira. Essa linha de pensamento, que remontaria aos viajantes estrangeiros que visitaram o Brasil durante o século XIX, passaria pelos escritores do romantismo e desembocaria nos cientistas nacionais que, como Oswaldo Cruz e Cândido Rondon, perscrutaram os sertões no início do XX, revela uma ação recorrente que expressa a relevância, abrangência e permanência do tema da identidade nacional correlacionado à questão das representações geográficas (Oliveira, 1990, 2000). ${ }^{1}$

1 "Configurou-se uma identidade nacional que toma argumentos geográficos, territoriais, como centrais e que integra o imaginário nacional. Isto se faz presente em trabalhos e livros de historiadores como Capistrano de Abreu, em seu 
Nessa direção, é lícito reconhecer que a permanência de determinadas imagens e concepções sobre Mato Grosso (Galetti, 2000; Maldi, 1992, 1997), ainda que com um conteúdo diverso ao longo dos anos, pode ter influenciado a elaboração de projetos que impactaram fortemente a configuração territorial (Santos, 1988) do estado. Põe-se então como fundamental a ligação que se tenta estabelecer entre as apropriações intelectuais do espaço e as ações empreendidas socialmente para sua efetiva produção. Portanto, destaca-se neste trabalho a preocupação de esclarecer as relações entre a execução das políticas territoriais, tidas como parte das políticas públicas desenvolvidas pelo Estado (Costa, 1988, 1992), e a formulação das ideologias geográficas (Moraes, 1988), concepções politicamente orientadas do espaço que podem vir a fundamentar esses projetos estatais.

Detalhando o tema ora em análise, essa comunicação busca elucidar as possíveis associações existentes entre o desenvolvimento de um imaginário de conquista, que toma a integração territorial dos sertões como imprescindível para a consolidação da soberania nacional, e a generalização de conceitos de base espacial no pensamento político-social brasileiro das primeiras três décadas do século XX. Essa circunstância pode sugerir que, antes mesmo da institucionalização universitário-acadêmica da geografia, formou-se no país um momento histórico propício para o desenrolar do processo de afirmação deste campo disciplinar.

\section{A questão pedagógica, o nacionalismo e a importância do discurso geo- gráfico}

Empreendendo uma apreciação da conjuntura histórica do Brasil no início do século XX, valeria indicar a importância dos temas da integração territorial e da expansão do povoamento para o debate político e intelectual do momento. Nesse pormenor, é importante citar o papel que a Sociedade de Geografia do Rio de Janeiro (SGRJ) cumpriu na elaboração de um projeto de saber disciplinar que visava fundamentar o conhecimento geográfico num corpo teórico específico. De fato, o esforço de socialização dos valores pátrios com vistas à adoção de um imaginário nacionalista por novos grupos e setores da sociedade por meio do ensino demandava sua transmissão por disciplinas consideradas científicas e, pois, exigia a renovação da geografia (Escolar, 1996).

A bem dizer, o período de 1910 a 1920, caracterizado decisivamente pela eclosão dos conflitos armados na Europa, em 1914, e pela Revolução Russa, em 1917, se distingue pela vulgarização do sentimento cívico e pela reafirmação dos interesses nas questões nacionais, que seguem identificando o sentimento de nacionalidade com o território. Tal condição explicita-se no chamado patriotismo à moda de 1914, que defendia o princípio das nacionalidades e a vontade de autodeterminação dos povos, e podia ser encontrado tanto nas intervenções do presidente americano Woddrow Wilson, como nas falas de Lênin nas conferências de paz de Paris, ocorridas entre 1919 e 1920 (Wallerstein, 2002).

Capitulos da história colonial (1907), em livros fundamentais da cultura nacional, como Os sertões (1902) de Euclides da Cunha. Continuará a se fazer presente em obras voltadas à explicação do Brasil mesmo em épocas mais recentes, como em Celso Furtado, na Formação econômica do Brasil (1959), onde cada ciclo econômico se passa em distinto espaço geográfico do país [...] no Brasil, a nação foi pensada como espaço territorial, como natureza, cabendo ao Estado a responsabilidade por garantir as fronteiras nacionais, mapear as riquezas e fomentar sua ocupação, assim como pela manutenção da unidade entre diferentes áreas isoladas e, mais tarde, pela integração entre tais áreas no todo nacional" (Oliveira, 2011, p. 129). 
No caso brasileiro, o período da I Guerra Mundial (1914-1919), que impulsionou uma revisão de nossos padrões intelectuais, reacendendo as discussões sobre o nacionalismo para além do simples ufanismo, marca o estabelecimento de um novo patamar de legitimação das intervenções nesse tema, agora definitivamente afastado dos cânones românticos. Imersa no clima generalizado de transformação cultural vivido no despontar dos anos 1920, que impunha a "necessidade de pensar o Brasil do ponto de vista brasileiro" (Oliveira, 1990, p. 126), a SGRJ entra numa nova fase, com o fim da gestão de Francisco Marcondes Homem de Mello, o barão Homem de Mello, e o início de uma sucessão de militares na presidência do grêmio. Nessa nova fase da SGRJ, o foco de interesses não estaria de maneira alguma restrito às minudências da questão pedagógica, senão que a geografia se colocava exatamente como um elemento estratégico na defesa da soberania nacional, vista, essa soberania, basicamente como resultado da integridade do território. De fato, a Grande Guerra chamara atenção para o uso de argumentos históricos como justificativa das reivindicações territoriais:

A proporção tomada pelo conflito europeu suscitou interesse crescente pela confecção de mapas e outras formas de representação espacial, uma vez que a maioria das reivindicações políticas sobre territórios nacionais assentava-se em argumentos históricos [...]. No Brasil, desde o final do século XIX, as autoridades republicanas preocupavam-se com a soberania e a preservação do espaço nacional. Se, por um lado, a vasta extensão territorial era motivo de ufanismo, por outro, o isolamento de algumas regiões, afastadas dos grandes centros e situadas nas faixas de fronteira, daria ensejo a diversos projetos de integração do território, a exemplo do da Comissão de Construção das Linhas Telegráficas, formada por militares, que integrou as comunicações entre Rio de Janeiro, São Paulo e Triângulo Mineiro à Amazônia. Paralelamente, o governo passou a conferir maior importância a entidades como a Sociedade de Geografia do Rio de Janeiro, reconhecida como órgão de utilidade pública [em 1917] por decreto do presidente Wenceslau Braz Pereira Gomes (Cardoso, 2010, p. 73.)

O pragmatismo dos trabalhos desenvolvidos e incentivados pela SGRJ, entre os quais destacam-se as expedições, que visavam esclarecer questões ainda sem consenso dentro da comunidade científica, se coaduna bem com as "obsessões geográficas", segundo o ideário positivista predominante na época. A definição das nascentes dos grandes rios, a exaltação da beleza e unicidade de um acidente geográfico, ou a atenção à fixação dos limites fronteiriços internos e externos, ações caras a uma República recém organizada, são exemplos da maneira como, entre o final do XIX e início do XX, a objetivação do nacional passava pela geografia e por categorias espaciais tanto quanto a construção de uma memória comum passava pela história (Pereira, 2003).

Como quer que seja, embora houvesse flagrante heterogeneidade e falta de correspondência entre os objetivos e os resultados da maioria dos empreendimentos patrocinados pela SGRJ, uma vez que boa parte das iniciativas não foram encaminhadas conforme o pretendido, ${ }^{2}$ não se pode subestimar o alcance dos projetos encampados pelo grêmio na difusão de um conhecimento geográfico sobre o país.

2 Lembre-se, por exemplo, o Dicionário de Geografia, de Alfredo M. Pinto, discutido como obra grandiosa desde 1884, mas publicado, em modestos três volumes, entre 1894 e 1899, e o compêndio Geografia do Brasil Comemorativa do Centenário, projeto de natureza enciclopédica integrante das comemorações do centenário da Independência, que foi planejado em 10 volumes para atingir o grande público, mas que foi editado, sem a periodicidade almejada, em incompletos apenas volumes. 
Para avaliar esse fato, bastaria fazer referência aos estímulos dados para a realização dos Congressos Brasileiros de Geografia (CBG), que costumam ser apontados como as iniciativas mais importantes da SGRJ. Forçoso é reconhecer que seus oito eventos, realizados entre 1909 e 1926, congregaram os esforços dos sujeitos interessados no desenvolvimento dos saberes geográficos, sobretudo aqueles passíveis de serem aproveitados pelo poder público. ${ }^{3}$

Outra ação relevante foi a organização, em 1926, do Curso Livre de Geografia, que reunia em seu corpo docente figuras expressivas da SGRJ e do Colégio Pedro II. Tendo como principais artífices Everardo Backheuser, Carlos Delgado de Carvalho e Fernando Raja Gabaglia, o plano pedagógico elaborado para guiar os trabalhos destacava a importância da relação homem-meio pela difusão das ideias de Ratzel e La Blache. Por isso, voltado para o aprofundamento da formação dos professores do ensino primário, o Curso Livre pode ser entendido como uma manifesta tentativa de organizar um projeto disciplinar para a geografia antes de sua efetiva institucionalização universitário-acadêmica (Zusman, 1996).

Essa iniciativa científico-pedagógica da SGRJ, que envolvia de algum modo a modernização do ensino pela incorporação das novas teorias e conceitos da geografia, foi em tudo similar ao empreendimento educacional nacionalista tentado anteriormente pelo Instituto Histórico e Geográfico Brasileiro (IHGB). Entre 1916 e 1921, o IHGB tentou estabelecer uma Academia de Altos Estudos, transformada posteriormente na Faculdade de Filosofia e Letras do IHGB. Embora ambas as iniciativas não tenham sido reconhecidas pelas autoridades, colocavam como objetivo comum a preocupação em desenvolver saberes geográficos passíveis de serem aplicados na explicação e resolução dos problemas nacionais.

A tentativa de entidades privadas, como a SGRJ e o IHGB, organizarem um curso de formação de professores, permite ressaltar a inexistência de um sistema organizado de educação pública no Brasil. Realmente, somente a partir da década de 1920 os debates em torno da necessidade de se criar uma estrutura pública e universal de ensino adquirem maior expressão, como atesta a fundação, no Rio de Janeiro, em 1922, da Academia Brasileira de Ciências, e em 1924, da Associação Brasileira de Educação, ambas com ativa participação dos já citados Everardo Backheuser e Delgado de Carvalho (Schwartzman, 2001).

Ao fim e ao cabo, ainda que se possa apontar a descontinuidade dessas ações, bem como a falta da chancela oficial, ambos os projetos encapavam a ideia de que a educação feita a partir de um efetivo conhecimento do território nacional era um dos caminhos mais seguros para alterar as condições precárias do ensino da disciplina no país. Além disso, personalidades como Basílio de Magalhães e José Maria Moreira Guimarães, quadros integrantes da SGRJ, haviam participado ativamente do empreendimento educacional do IHGB, o que reforça a convergência entre os projetos. Evidenciando as tendências teóricas mais recentes da geografia praticada na época, a referência a esses projetos ajudam a identificar o estopim dado no início do século XX para a conformação de um ambiente estruturado de reprodução continuada dos saberes geográficos num campo disciplinar reconhecido e organizado.

3 Os dois últimos congressos, ocorridos em Florianópolis e no Rio de Janeiro, respectivamente em 1940 e 1944, inscrevem-se num contexto sobremodo diferente dos anteriores, já que então se assistia à convivência inédita da SGRJ com as universidades, a Associação de Geógrafos Brasileiros (AGB) e o Instituto Brasileiro de Geografia e Estatísticas (IBGE), instituições que hegemonizam a organização da geografia em moldes acadêmicos e profissionais ao longo da década de 1930. 


\section{A visão geopolítica e a integração do território}

Sem embargo, para além do horizonte pedagógico de então, é preciso notar que a discussão estratégica e geopolítica é sem dúvida fundamental na caracterização do ambiente intelectual das três primeiras décadas do século XX. No geral, os discursos geoestratégicos tomavam o território e seus componentes, tais como a dimensão, as fronteiras, os recursos naturais, a população, a posição, a situação e as condições de deslocamento internas, entre outros, como temas centrais das discussões que intentavam elaborar verdadeiros projetos nacionais para o Brasil. Haveria até a coincidência de certos nomes, pois Everardo Backheuser, Carlos Delgado de Carvalho e, em certo sentido, até mesmo o capitão do Exército Mário Travassos, precursores das discussões e pesquisas geopolíticas em nosso país, frequentavam de modo simultâneo associações como a Associação Brasileira de Ensino (ABE), o Itamaraty, o IHGB e a SGRJ. Essas figuras desempenhavam um papel de destaque nos círculos intelectuais próximos dos debates de cunho geoestratégico, mas não deixavam de participar das atividades que esboçaram uma sistematização da geografia acadêmica antes da institucionalização universitária da disciplina (Anselmo, 2000; Vlach, 2003).

$\bigcirc$ debate sobre a transferência da capital do Brasil para o interior, que remonta desde ao menos a Varnhagen e não pode ser dissociada das discussões que envolvem a vontade estatal de incorporar os sertões brasileiros à civilização (Lima, 2010), pode ser visto como um dos principais exemplos da continuidade do tema da coesão territorial no ambiente político e intelectual brasileiro entre o final do século XIX e início do século XX. Nessa passagem de século, a vertente geopolítica do pensamento político-social brasileiro já colocava as questões associadas da integração territorial e da circulação interna do território como fatores fundamentais a serem resolvidos para que o desenvolvimento e a consequente modernização do país fossem bem encaminhados (Costa, 1992; Miyamoto, 1981).

A proeminência de uma visão espacializada do país, percebida por exemplo na vulgarização das leituras que qualificavam como benéficas ou deletérias as características físicas e mesmo sociais (estas vistas por um prisma naturalizador) do território, parece solidificar-se como um dos cernes explicativos da realidade nacional. Erigindo uma espécie de determinismo biomesológico que questiona o papel do meio tropical e da população miscigenada no desenvolvimento do país, esse arranjo explicativo formula um enunciado que traz consigo um intrigante paradoxo: o território brasileiro e a população nele fixada encerrariam um potencial de riquezas ainda não exploradas pelo Estado ou seriam mesmo a motivação principal de nosso atraso? Com qual povo contamos para alavancar nosso progresso?

Entre as principais ações pensadas para resolver os problemas postos pelo paradoxo que opunha as potencialidades do território (leia-se sua natureza) ao atraso da população, interessa-nos a promoção de uma série de políticas governamentais voltadas para a organização de uma renovada configuração territorial. Nessa ótica, o planejamento e execução de medidas visando a reorganização dos fixos e fluxos no espaço brasileiro apresentavam-se como a solução dos problemas relativos ao atraso social e econômico do país, que seriam atenuados pelo estímulo à ocupação, povoamento e consequente indução do desenvolvimento industrial e agrário no Brasil, temas recorrentes na vertente geopolítica que informava o núcleo do pensamento autoritário disseminado na época (Bomfim, 2001). 
As vantagens que a otimização do sistema de transportes traria à circulação, vista como um fator geográfico que preocupa a prática política dos Estados, transformam a coesão política de um Estado em tributária da intensidade dos fluxos encetados no sentido de comprimir as tendências centrífugas presentes no território (Gottman, 1952). Contudo, é mesmo na interligação entre os pontos extremos do território nacional que o problema adquire imenso potencial estratégico, articulando o desenvolvimento de um sistema de comunicações com os objetivos das políticas de povoamento, defesa de fronteiras e integração econômica.

A discussão sobre a necessidade de construir uma rede de comunicações que reduzisse as distâncias continentais a serem vencidas no território brasileiro via-se sempre às voltas com a percepção que se tinha das terras distantes do litoral no início do século XX. Aos olhos dos habitantes das grandes cidades próximas ao Oceano Atlântico, o Norte e o Noroeste do país eram vistos como áreas apartadas do território nacional, lugares isolados verdadeiramente perdidos em meio a um imenso vazio (Maciel, 1998, 1999). Com efeito, apesar dos esforços dos viajantes que desde o final do século XVIII se embrenharam em missões de reconhecimento do território luso-americano, nos mapas e compêndios geográficos existentes nos lustros iniciais do Novecentos, o interior do Brasil em geral, e o Mato Grosso em específico, figuravam como "terras incógnitas habitadas por índios", sinônimo de desertos selvagens à espera de integração à civilização.

Ora, se lembrarmos que a conquista e colonização europeia do Brasil central data desde ao menos o início do século XVIII, quando a exploração de ouro e diamantes nas antigas capitanias de Goiás e Mato Grosso canalizou intensos fluxos migratórios para a região, essa imagem de espaço vazio inteiramente desconhecido não deveria se sustentar com tanto apelo ao público letrado no início do século XX. ${ }^{4}$

Porém, levando em conta que desde o fim da Guerra do Paraguai a necessidade de construção de uma ligação direta entre o Rio de Janeiro e Mato Grosso era vista como ação incontornável para a defesa dos limites e fronteiras internacionais, bem como o fato de que entre a antiga capital federal e o sertão mato-grossense havia efetivamente diversos vazios demográficos que dificultavam a afirmação do poder estatal, vê-se que, do ponto de vista geoestratégico compartilhado por boa parte dos intelectuais que orbitavam as Forças Armadas, a qualificação de Mato Grosso como área isolada e inalcançável poderia ajudar a legitimar, junto à opinião pública, o esforço estatal de construir próteses territoriais como o telégrafo e as ferrovias, que intermediariam a integração, a administração e a vigilância das áreas lindeiras do território brasileiro, efetivando a modernização do Estado e a dilatação do mapa do país.

\section{A apropriação tecnocientífica do território: as Expedições Civilizatórias}

Nos estudos de história da geografia que conferem à institucionalização da disciplina papel de destaque, a formação de um discurso técnico-científico a respeito do território brasileiro é normalmente associada à sistematização unificada de dados estatísticos e

4 Como consequência desse processo de ocupação que remonta ao período colonial, seria possível inclusive identificar, nos anos imediatamente anteriores ao processo de emancipação política do país, em 1822, as diverentes funções exercidas pela rede de cidades situada a leste do Araguaia goiano, que marcava os limites do território usado em terras luso-brasileiras, e os fortes e vilas planejadas que davam uma feição geopolítica ao Mato Grosso, que resguardava como um posto avançado os limites rarefeitos da pretensão de soberania territorial herdada dos colonizadores lusitanos pelo nascente Estado imperial (Nogueira, 2012). 
cartográficos que desemboca na fundação do Instituto Brasileiro de Geografia e Estatísticas (IBGE) ao longo da década de $1930 .{ }^{5}$ Contudo, há que se observar que o incentivo ao esquadrinhamento instrumental do território para fundamentar as tomadas de decisão pela esfera política não se iniciou, no Brasil, com a fundação do dito instituto. Na verdade, Silvia Figueirôa (1997) e Heloísa Domingues (1995) são bem-sucedidas em indicar a maneira como, desde ao menos o final do Império, foram constituídas comissões de naturalistas e cientistas voltadas para o mapeamento das condições naturais do território visando a incorporação produtiva de áreas consideradas vazias ou não exploradas. A Comissão Geológica Imperial, de 1875, a Comissão Hidrográfica do Império, de 1879, e a Comissão Geográfica e Geológica (CGG), de 1886, que tinham a intenção de aperfeiçoar a exploração econômica de potenciais recursos naturais e humanos presentes no território, bem demonstram o papel fundamental da ciência e da técnica na elaboração de estratégias de apropriação territorial (Figueirôa, 2008).

Idealizada e dirigida em São Paulo pelo geólogo e naturalista Orville A. Derby (18511915), a CGG sintetizava a vitória de um caminho tecnocientífico como alternativa viável para solucionar os problemas que a economia do café vivia ao final do século XIX. Os relatórios produzidos pelas expedições por ela patrocinadas se inscreviam em diversas áreas do conhecimento - geografia, geologia, botânica, meteorologia e hidrologia, entre outras -, o que permite compreendê-los, e à própria CGG, como uma espécie de matriz para o ensino e a prática de inúmeros ramos das ciências naturais e geológicas. ${ }^{6}$

Além das atividades da Comissão Geográfica e Geológica, poder-se-iam citar outros exemplos de expedições que, ao estabelecer uma apropriação científica do território, elaboravam imagens às quais subjaz a ideia de construir o país, que seria assim identificado como um espaço a ser conquistado, e não como uma sociedade. A propósito, em seus estudos sobre o processo brasileiro de formação territorial, Antônio Carlos Robert Moraes (2000, 2002, 2011) trabalha com um argumento que reconhece a existência de uma espécie de razão de Estado, comum a países de formação colonial, que sói identificar o Brasil a seu território, e não a sua sociedade. Reverberando uma visão instrumental dos segmentos populares e servindo como justificativa à elaboração de diferentes estratégias de apropriação territorial, essa concepção espacialista do Brasil, continuamente reposta em formulações diversas desde ao menos meados do século XIX, enraíza-se na ideia de construção do país, mote ideológico que passa a informar um projeto nacional imiscuído numa ótica geopolítica:

5 Em texto do início da década de 1990, Marcelo Escolar (1996) faz uma resenha exaustiva das interpretações e alternativas historiográficas existentes sobre a história da geografia, situando e qualificando a distinção entre os enfoques "internalista" e "externalista" do campo disciplinar no quadro mais amplo do debate que trata da história das ciências em geral. Comentando as interpretações e os principais trabalhos produzidos até então, o geógrafo argentino oferece também um possível caminho, propondo uma história social da geografia, modalidade analítica que visa privilegiar a gênese do contexto de justificação epistemológica do discurso geográfico sem partir de uma evidência institucional prévia. Para uma discussão dos caminhos historiográficos trilhados pelos que se aventuram a contar a história da geografia, ver também o artigo de Nilson Crocia de Barros (2006).

6 Esse protagonismo é reconhecível na influência que da CGG na organização de diversas instituições até hoje existentes e atuantes no sistema científico e tecnológico paulista tais como o Instituto Geológico, o Instituto Geográfico e Cartográfico, o Instituto de Botânica, o Instituto Florestal, o Instituto Astronômico e Geofísico, o Museu Paulista e o Museu de Zoologia. 
O padrão discursivo básico do século XIX que conforma essa concepção estrutura-se em torno do conceito de civilização, atribuindo portanto à monarquia brasileira uma missão civilizadora. Construir o país é levar a civilização aos sertões, ocupar o solo é subtrair os lugares da barbárie, o que cabe a uma elite que se auto-define como "representante das idéias da Ilustração" [...]. O papel catalisador que a noção de "civilização" cumpriu para a antiga mentalidade será agora ocupado pelo conceito de modernização. Tal conceito, central no pensamento brasileiro do século XX, reveste-se também de densa espacialidade. Pode-se dizer que modernizar é, entre outras coisas, reorganizar e ocupar o território, dotá-lo de novos equipamentos e sistemas de engenharia, conectar suas partes com estradas e sistemas de comunicação. Enfim, modernização implicava no caso brasileiro necessariamente valorização do espaço. Nesse sentido, o país podia ser novamente equacionado como âmbito espacial no qual o Estado devia agir para instalar o novo projeto nacional: a construção do Brasil moderno (Moraes, 2002, p. 118/121.)

Analisando as expedições de intelectuais e cientistas que se dirigiam ao interior do país no início do período republicano, Nísia Trindade Lima (1999) afirma o dualismo entre sertão e litoral como integrante de um campo semântico que entendia o sertão como um lugar afastado do poder público e de seus projetos modernizadores, um lugar a ser incorporado ao Estado e à nação por processos de civilização e conquista que garantiriam o progresso. A concepção do sertão como lugar insalubre e enfermo que retardava o avanço do país, ajudou a compor uma imagem na qual metáforas organicistas serviam indistintamente para qualificar a sociedade e o território, repondo a questão da população com que o Brasil contaria para se modernizar. Enfim, o sertão e sua população, fatores indissociáveis, eram compreendidos como patologias nacionais, problemas que somente seriam superados pelas ações de saneamento e educação comandadas, evidentemente, pelo cientificismo da maior parte dos envolvidos:

Compreendendo o interior do país como um vasto espaço vazio, em branco, habitado por populações ainda "arredias à civilização", que representavam barreiras ou limites ao avanço da República, os engenheiros militares ligados à Comissão Rondon defendiam a necessidade de ocupar esses espaços e dilatar as "fronteiras da Pátria" como um dever do Estado a ser conduzido pelo exército, "as forças armadas da nação". Filiados a uma tradição do pensamento positivista e evolucionista, eles defendiam uma perspectiva civilizatória do progresso técnico-científico em que a comunicação telegráfica despontava como um dos mecanismos para manutenção da ordem pública (Maciel, 1999, p. 167).

A Comissão Construtora das Linhas Telegráficas, organizada pelo Estado republicano para efetuar a ligação entre Goiás e Mato Grosso (1891-1898), mais precisamente entre Cuiabá e Registro do Araguaia, prolongou-se na chamada Comissão de Mato Grosso (1900-1906), que buscava interligar a capital cuiabana com outras cidades mato-grossenses. Ambas as co- 
missões, que contavam com a destacada participação do engenheiro militar Cândido Mariano da Silva Rondon, que inclusive liderou a de Mato Grosso, visavam integrar o interior do país ao sistema de telégrafos já existente no Rio de Janeiro, São Paulo e Minas Gerais. ${ }^{7}$

A partir de 1907, novamente chefiada por Cândido Rondon, constituiu-se a Comissão de Linhas Telegráficas e Estratégicas de Mato Grosso ao Amazonas (CLTEMTA) (19071915). Embora inúmeros comentadores já tenham avaliado o caráter "civilizatório" da CLTEMTA (Bigio, 2000; Diacon, 2006; Lima, 1998), alguns estudos recentes dedicados à história da ciência vêm destacando o papel das expedições efetuadas no âmbito da Comissão na produção de um inventário dos recursos naturais do território. Realmente, a incorporação de naturalistas, botânicos, geólogos e zoólogos nos quadros da Comissão dá força ao enunciado que entende que no processo de formação territorial, a apropriação e domínio do espaço comporta igualmente um campo que valoriza o trabalho intelectual, relacionando as imagens produzidas a respeito do território ao processo de sua efetiva transformação:

Na Comissão de Mato Grosso ao Amazonas, ciência, caminhos e comunicações adentraram o extremo norte do país juntos, e, nessa conjunção, era persistente a visão de que na Amazônia, sobretudo, caberia, a um só tempo, o "sertão" como abandono por parte dos poderes públicos e "paisagem" destinada a desaparecer; o "território vazio" a ocupar, povoar e modernizar; a "fronteira" a delimitar e precisar nos confins do país; a "floresta" e seus animais, doenças e rios encachoeirados; e, foco principal do nosso interesse neste artigo, o 'campo' inaudito para estudos, pesquisas e levantamentos científicos (Sá; Sá; Lima, 2008, p. 783).

No caso, sob o nome genérico de Comissão Rondon, agrupa-se o conjunto de viagens e atividades desenvolvidas por cientistas e militares brasileiros no intervalo de 1900 a 1930 . Além das expedições construtoras de telégrafos já citadas, é possível colocar sob esse rótulo os serviços de administração e conservação das estações e linhas telegráficas, os inúmeros relatórios com a sistematização de resultados, a fundação e consolidação do Serviço de Proteção aos Índios e Localização dos Trabalhadores Nacionais e os trabalhos de Inspeção de Fronteiras, todos realizados sob o comando de Rondon:

principal objetivo da Comissão era conhecer, integrar, aproximar espaços tidos como afastados e atrasados e transformá-los em áreas produtivas, preparando-as para uma ocupação que deveria ir à esteira das melhorias da infraestrutura local. $\bigcirc$ conhecimento destes territórios seria pautado por levantamentos de cunho

7 Trechos dos apontamentos de Rondon a respeito dos trabalhos desenvolvidos pela Comissão de Mato Grosso, publicados como artigos do Jornal do Comércio, no Rio de Janeiro, em 1915, deixam claros os objetivos perseguidos: "[...] tornava-se preciso encerrar os principais pontos estratégicos dos confins do Brasil com o Paraguai e a Bolívia, nas malhas duma grande rede telegráfica, cujos fios, enfeixando-se em Cuiabá, permitissem ao governo central e à nação estar em constante comunicação com aquelas longínquas paragens do nosso território e sobre elas exercer ativa e proveitosa vigilância [...]. Os trabalhos de construção dessa rede abrangeram o período compreendido de 1900 a 1906, ano em que ela ficou acabada, com 1.746 quilômetros e 813 metros de fios, servindo 17 estações. A fronteira do Paraguai ficou ligada por dous pontos principais - Porto Murtinho e Bela Vista - e a da Bolívia por outros dous Corumbá e Coimbra -, sem contar com um terceiro, S. Luís de Cárceres, sede, como os demais, de estacionamento de forças militares, mas não colocado, como aqueles, quase sobre a linha que marca a terminação do território brasileiro" (Rondon, 2003, p. 34). 
geográfico se valendo de rios como caminhos. $\bigcirc$ telégrafo viria acompanhando, atravessando e margeando importantes rios da região, entre eles o Madeira e o Juruena, por exemplo. $\bigcirc$ planejamento era ampliar a linha já existente entre o Rio de Janeiro e o Mato Grosso. De Cuiabá, o telégrafo iria até Santo Antônio do Madeira; além desta linha principal, chamada linha tronco, mais três ramais deveriam ser construídos: para o Acre, Purus e Juruá, ficando a cargo da Comissão a escolha do ponto a partir do qual a linha seria estendida até Manaus. Os pontos extremos da linha seriam Cuiabá, Santo Antônio do Madeira e Manaus. A construção do telégrafo em meio à floresta dependia diretamente dos reconhecimentos territoriais, pois eles eram imprescindíveis para o próprio avanço da construção da linha telegráfica (Aranha, 2012, p. 92-93).

Vinculada institucionalmente a distintos ministérios, como o Ministério da Guerra, o Ministério da Viação e o da Agricultura, Indústria e Comércio, a Comissão Rondon foi se transformando ao longo dos anos. Ao articular as tarefas demandadas pelos diferentes órgãos aos quais se vinculava, ela foi formulando novos objetivos para modificar suas atribuições e alterando seus interesses a partir do trabalho mais específico que iria desenvolver. Quanto à produção científica de seus membros, nota-se o crescimento do caráter utilitário da Comissão a partir da participação ativa de cientistas do Museu Nacional em suas viagens, o que denota o relevo dos trabalhos de reconhecimento do potencial de exploração do território:

A propósito, os relatórios da Comissão Construtora de Linhas Telegráficas de Mato Grosso ao Amazonas ilustram bem a combinação entre os objetivos mais imediatos e "pragmáticos" - de efetivar a integração dos sertões e a exploração dos recursos naturais do norte do país - às preocupações e ao estilo de trabalho típicos dos naturalistas: volumosas descrições de espécimes da flora e da fauna; detalhadas descrições geográficas e geológicas acompanhadas de pranchas primorosas; glossário de termos presentes em línguas de vinte nações indígenas (Sá; Sá; Lima, 2008, p. 788).

Essas "missões civilizatórias", eivadas de um ideário cientificista, operaram um esforço de valorização do sertão, "seja enquanto espaço a ser incorporado ao esforço civilizatório das elites políticas do país, seja como referência da autenticidade nacional" (Lima, 1999, p. 65). A preponderância do tema da integração do interior do território nacional no pensamento político-social brasileiro, fica esboçada nas imagens utilizadas pelos partícipes dessas missões na descrição de seus trabalhos. Em uma conferência proferida em 1920 na cidade de Piracicaba, no interior de São Paulo, significativamente intitulada "Rumo ao Sertão", Cândido Rondon exprime com clareza a relação que comumente se estabelecia na época entre a interiorização do povoamento, a conquista dos sertões do Brasil central e o futuro desenvolvimento econômico do país, colocando a questão nos seguintes termos:

$\bigcirc$ problema brasileiro, a meu ver, que de nós mais carinho está a exigir, é o do sertão, ou seja, do seu útil povoamento. É para o sertão que os nossos melhores esforços deviam convergir, na conquista das fabulosas riquezas que a nossa aben- 
çoada Terra guarda e conserva com o carinho e zelo da Mãe Extremosa. Desvendar essas riquezas, pô-las ao alcance dos capitais humanos capazes de incrementar o progresso do Brasil incomparável, seria serviço de alto alcance patriótico, a que todos os brasileiros deviam com entusiasmo entregar-se [...]. A expansão deve estender-se terra adentro, no sentido natural em que se tem efetuado todo o progresso humano. Em busca do Oeste as novas gerações brasileiras deviam estender-se formando a coorte moderna dos conquistadores das matérias primas para a grande indústria. Penetrar o sertão levando nas mãos a força da indústria moderna, eis o ideal pelo qual deviam as novas gerações nortear a sua atividade e a sua inteligência (Rondon, 1922, p. 57-58).

Na fala de Rondon, o espaço denominado sertão não se apresenta como uma área localizável e cartografável dotada de certa homogeneidade e individualidade, "não podendo ser estabelecido como um tipo de meio natural singular nem como uma modalidade própria de paisagem humanizada" (Moraes, 2009, p. 88). Logo, conclui-se que o sertão, uma das categorias centrais das construções literárias e ensaísticas que tinham a nação e seu processo de formação como tema (Amado, 1995), não se refere a uma realidade fático-material, nem a uma paisagem típica presente no universo empírico da geografia clássica. Isso nos leva a asseverar que, nesses registros, o sertão é uma condição atribuída, em circunstâncias determinadas, a diversos lugares. Em outros termos, a definição do sertão inclui a projeção de uma valorização futura que irá mudar a condição atual da área assim qualificada. ${ }^{8}$

Em suma, necessidade de implantação de mecanismos de controle técnico e científico sobre o território, pode ter sido o alicerce de algumas das propostas de reconhecimento das terras interiores do Brasil, encetadas inúmeras vezes na primeira metade do século XX. Para os agentes públicos envolvidos nessas expedições, ao dominar a natureza intocada dos sertões, o Estado estaria construindo o país ao mesmo tempo em que o inseria na modernidade. Em vista disso, a organização dessas missões pode ser entendida como parte de um movimento de forte conteúdo simbólico que acompanhava os projetos políticos então em desenvolvimento.

Nesse sentido, o domínio material dos sertões, que se faria pela construção dos telégrafos, que aprimorariam os fluxos internos engendrados no território brasileiro, aliado à apropriação simbólica dos espaços vazios, que se faria pelos inventários científicos elaborados pela Comissão Rondon, tornar-se-iam fatores de integração nacional, atuando como veículos de difusão da modernidade no espaço.

8 "Enfim, o sertão é uma figura do imaginário da conquista territorial, um conceito que, ao classificar uma localização, opera uma apropriação simbólica do lugar, densa de juízos valorativos que apontam para sua transformação. Nesse sentido, a designação acompanha-se sempre de um projeto (povoador, civilizador, modernizador, integrador), o qual almeja - no limite - a superação da condição sertaneja. Trata-se de um espaço a ser conquistado, submetido, incorporado à economia nacional: uma área de expansão. Por essa característica, é possível estabelecer paralelos entre o papel desempenhado pela idéia de sertão na formação brasileira e o uso similar da noção de 'deserto' na história da Argentina. No plano conceitual, mas mais distante de conteúdo em função de seu componente democrático (não presente nos conceitos anteriores), estaria a 'fronteira' - tal como analisada por Turner - na colonização dos Estados Unidos. Temse o sertão como um qualificativo de lugares, um termo da geografia colonial que reproduz o olhar apropriador dos impérios em expansão. Na verdade, trata-se de sertões, que qualificam caatingas, cerrados, florestas, campos. Um conceito nada ingênuo, veículo da difusão da modernidade no espaço" (Moraes, 2009, p. 97-98). 


\section{Considerações finais}

Na perspectiva dos saberes geográficos produzidos pela Comissão Rondon, a preparação de um cabedal de informações para a produção de extenso material cartográfico confere destaque à Carta de Mato Grosso, publicada em 1952, a partir dos levantamentos de campo efetuados durante as expedições (Bernardino, 2015). Além disso, o trabalho de normalização dos topônimos, a identificação de serras e o detalhamento de cursos de rios, com o levantamento de todos os afluentes brasileiros do rio Paraguai e o mapeamento de 12 rios até então desconhecidos (Nomura, 2010), têm em comum a forma da coleta e da apresentação dos dados, bem como seu caráter utilitário, uma vez que o conhecimento produzido deveria servir como base para a implementação de políticas territoriais que levariam ao progresso e à civilização das regiões descritas (Aranha, 2012).

A participação de eminentes nomes da ciência nos trabalhos desenvolvidos pela Comissão em suas diferentes fases - como Frederico Carlos Hoenne (1882-1959), Alípio de Miranda Ribeiro (1874-1939) e Edgard Roquette-Pinto (1884-1954) - reforça a contribuição das expedições para a consolidação de inúmeros campos disciplinares como a botânica, a zoologia e a antropologia. Expressivamente, contando apenas o intervalo entre 1907 e 1915, o patrimônio recolhido pela Comissão Rondon para o Museu Nacional "superava proporcionalmente os 100 anos anteriores de constituição de acervo. Havia mais diversidade e variação de exemplares no material recolhido pela Comissão: 8.837 exemplares botânicos, 5.676 espécimes zoológicos e 3.380 artefatos indígenas" (Freire, 2009, p. 68).

A preocupação em integrar as áreas qualificadas como sertão por meio da construção dos telégrafos e do desenvolvimento de projetos de colonização, considerada uma das bandeiras da República, que assim se contrapunha à estagnação dos tempos do Império (Maciel, 2001), indica que a implantação dessas próteses territoriais era considerada ação incontornável para efetivar a mudança que se projetava. Ademais, o debate a respeito dos potenciais benefícios oriundos da conquista tecnocientífica das terras interiores do país, traduzia um ambiente no qual a necessidade de mostrar internacionalmente uma nação ajustada sincronicamente ao progresso do mundo desenvolvido passava pela materialização das obras de modernização do território (Duarte, 2013).

Enfim, ao longo da primeira metade do século XX, é perceptível a existência de um conjunto de discursos reiteradamente desdobrados em influentes ideologias geográficas (Moraes, 1988) que em seu conteúdo fundamental repõem, sempre em novas bases, a relação entre a conquista do território, o desbravamento dos sertões e o progresso econômico. No tocante à produção simbólica do espaço, o ideal de construção de um Brasil moderno, vislumbrado nas interpretações míticas a respeito dos resultados imediatos da Comissão Rondon, que teria conseguido "civilizar" os sertões selvagens, foi desdobrado nas ações heterogêneas que tinham em comum a finalidade da ocupação demográfica e econômica do interior do país. Já quanto ao uso de imagens e conceitos de base espacial pelo pensamento político-social, é pertinente notar a continuidade da discussão acerca da conquista e construção do território mesmo após a década de 1930 (Maia, 2010).

A reiteração de uma abordagem que concebe o país como sinônimo de seu território e o interior do território como um espaço a ser apropriado e conquistado material e intelectualmente, aponta a existência, dentro do pensamento político-social, de uma demanda pela siste- 
matização de diagnósticos precisos acerca dos problemas enfrentados pelo país. Posteriormente, essa circunstância abriria a possibilidade de a geografia acadêmica aparecer no horizonte da vida intelectual brasileira como uma modalidade discursiva que tenta apreender a realidade a partir de ferramentas analíticas e metodológicas voltadas para esse fim. Mesmo assim, isso pode indicar que, num momento anterior à institucionalização universitária do campo disciplinar, já estaria maduro um ambiente propício à generalização daquilo que se pode chamar de uma cultura geográfica (Cardoso, 2011).

O estudo pormenorizado do imenso conjunto de documentos legado pelas chamadas "missões civilizatórias", com a identificação dos problemas postos na época a alguns personagens hoje não tão lembrados, acena para a consolidação de um campo de pesquisa que permanece bem ou mal descoberto nos trabalhos dedicados a contar a história da geografia, uma vez que permite examinar a emergência de conjunturas oportunas à construção de análises geográficas do real sem se prender a uma demarcação institucional prévia.

Depois da década de 1930, com a criação dos cursos universitários e a vulgarização de um tipo de análise surgido a partir da consolidação do campo disciplinar numa situação de afirmação institucional, fundamenta-se um registro discursivo próprio que, numa visão retrospectiva, se mostrou eficaz na criação de uma expressiva tradição intelectual (Nogueira, 2013). A generalização de um tipo de texto que se pode qualificar como uma monografia regional descritivo-explicativa, que aparece como o estilo modelar de escrita científica da geografia no espaço acadêmico-universitário nacional, acaba por consagrar um novo tratamento a ser dado a antigos problemas, que ganham agora um verniz de cientificidade e pragmatismo que se quer o oposto do diletantismo antes dominante. No caso da geografia acadêmica, a questão da colonização e do povoamento das terras interiores estimula a produção de uma ampla bibliografia, seja vinculada ao planejamento estatal, seja referente às pesquisas conduzidas na universidade (Adas, 2007; Nogueira, 2015).

No fim, a permanência de temas como a apropriação dirigida dos espaços considerados vazios e a integração do território, que desde o fim do século XIX integravam a preocupação de intelectuais, classes dirigentes e agentes do Estado, pode, no limite, indicar traços de continuidade de determinados assuntos que, alçados ao patamar de questões nacionais, catalisaram estudos e receberam tratamentos distintos de diversas áreas do saber. Essa particularidade permite pensar num enquadramento analítico que questiona o papel do pensamento geográfico nesse movimento, incorporando-o à apreciação do processo de formação do pensamento político-social brasileiro.

\section{Referências}

ADAS, S. O campo do geógrafo: colonização e agricultura na obra de Orlando Valverde (1917-1964). Tese (Doutorado em Geografia Humana) - Faculdade de Filosofia, Letras e Ciências Humanas, Universidade de São Paulo, São Paulo, 2007.

AMADO, J. Região, sertão e nação. Estudos Históricos, Rio de Janeiro: CPDOC/FGV, v. 8, n. 15, p. 145-151, 1995. 
ANSELMO, R. C. M. S. Geografia e geopolítica na formação nacional brasileira: Everardo Adolpho Backheuser: Tese (Doutorado em Geografia) - Universidade Estadual Paulista, Rio Claro, 2000.

ARANHA, P. M. Levantamentos territoriais e construção de saberes geográficos na Comissão de Linhas Telegráficas Estratégicas do Mato Grosso ao Amazonas (1907-1915). Revista Brasileira de História da Ciência, Rio de Janeiro, v. 5, n. 1, p. 91-100, jan./jun. 2012.

BARROS, N. C. C. A historiografia da geografia e suas controvérsias: apreciação de um debate. Revista Geográfica de Instituto Panamericano de Geografia e História, México, n. 139, p. 83-102, 2006.

BERNARDINO, M. G. Redesenhando a fronteira Noroeste. Terra Brasilis (Nova Série), n. 6, 2015. Disponível em: http://journals.openedition.org/terrabrasilis/1656. Acesso em: 7 mar. 2018.

BIGIO, E. S. Cândido Rondon: a integração nacional. Rio de Janeiro: Contraponto/Petrobras, 2000.

BOMFIM, P. R. A. Território e movimento integralista: uma contribuição ao estudo das ideologias geográficas no pensamento autoritário brasileiro das décadas de 1920 1930. Dissertação (Mestrado em Geografia Humana) - Faculdade de Filosofia, Letras e Ciências Humanas, Universidade de São Paulo, São Paulo, 2001.

BOURDIEU, P. O poder simbólico. Rio de Janeiro: Bertrand Brasil, 1989.

CARDOSO, L. P. C. Os congressos brasileiros de geografia entre 1909 e 1944. História, Ciências, Saúde - Manguinhos, Rio de Janeiro, v. 18, n. 1, p. 85-103, jan./mar. 2011.

Sociedade de Geografia do Rio de Janeiro: espaço de invenção do patriotismo nas primeiras décadas do séc. XX. Revista Brasileira de História da Ciência, Rio de Janeiro, v. 3, n. 1, p. 68-84, jan./jun. 2010.

COSTA, W. M. Geografia política e geopolítica: discursos sobre território e poder. São Paulo: Edusp/Hucitec, 1992.

O Estado e as políticas territoriais no Brasil. São Paulo: Contexto, 1988.

DIACON, T. A. Rondon: o marechal da floresta. São Paulo: Companhia das Letras, 2006.

DOMINGUES, H. M. B. Ciência, um caso de política: ciências naturais e agricultura no Brasil Império. Tese (Doutorado em História Social) - Faculdade de Filosofia, Letras e Ciências Humanas, Universidade de São Paulo, São Paulo 1995.

DUARTE, R. B. Incógnitas geográficas: Francisco Bhering e as questões territoriais brasileiras no início do século XX. São Paulo: Alameda, 2013.

ESCOLAR, M. Crítica do discurso geográfico. São Paulo: Hucitec, 1996.

FIGUEIRÔA, S. "Batedores da ciência" em território paulista: expedições de exploração e a ocupação do "sertão" de São Paulo na transição para o século XX. História, Ciências, Saúde - Manguinhos, Rio de Janeiro, v. 15, n. 3, p. 763-777, jul./set. 2008. 
As ciências geológicas no Brasil: uma história social e institucional, 1875-1934. São Paulo: Hucitec, 1997.

FREIRE, C. A. R. Rondon: a construção do Brasil e a causa indígena. Brasilia: Abravideo, 2009.

GALETTI, L. S. G. Nos confins da civilização: sertão, fronteira e identidade nas representações sobre Mato Grosso. Tese (Doutorado em História Social) - Faculdade de Filosofia, Letras e Ciências Humanas, Universidade de São Paulo, São Paulo, 2000.

GOTTMAN, J. La politique des États et leur géographie. Paris: A. Colin, 1952.

LIMA, N. T. Brasilia: a capital no sertão. In: SENRA, N. (Org.). Veredas de Brasília: as expedições geográficas em busca de um sonho. Rio de Janeiro: IBGE, 2010.

Um sertão chamado Brasil: intelectuais e representação geográfica da identidade nacional. Rio de Janeiro: Revan, 1999.

Missões civilizatórias da República e interpretação do Brasil. História, Ciências,

Saúde - Manguinhos, Rio de Janeiro, v. 5, p. 163-193, 1998. Suplemento.

MACIEL, L. A. Cultura e tecnologia: a constituição do serviço telegráfico no Brasil. Revista Brasileira de História, São Paulo, v. 21, n. 41, p. 127-144, 2001.

A Comissão Rondon e a conquista ordenada dos sertões: espaço, telégrafo e civilização. Projeto História, São Paulo, v. 18, p. 167-189, maio 1999.

A nação por um fio: caminhos, práticas e imagens da "Comissão Rondon". São Paulo: Educ, 1998.

MAIA, M. E. As ideias que fazem o Estado andar: imaginação espacial, pensamento brasileiro e território no Brasil Central. Dados - Revista de Ciências Sociais, Rio de Janeiro, v. 53, n. 3, p. 621-655, 2010.

A terra como invenção: o espaço no pensamento social brasileiro. Rio de Janeiro: Jorge Zahar, 2008.

MALDI, D. De confederados a bárbaros: a representação da4 territorialidade e da fronteira indígenas nos séculos XVIII e XIX. Revista de Antropologia, São Paulo, v. 40, n. 2, p. 183-221, 1997.

MALDI, D. Pantanais, planícies, sertões: uma reflexão antropológica sobre espaços brasileiros. Boletim Paulista de Geografia, São Paulo: AGB, n. 71, 10 sem. 1992.

MARTIN, A. R. As fronteiras internas e a questão regional do Brasil. Tese (Doutorado em Geografia Humana) - Faculdade de Filosofia, Letras e Ciências Humanas, Universidade de São Paulo, São Paulo, 1993.

MIYAMOTO, S. O pensamento geopolítico brasileiro (1920-1980). Dissertação (Mestrado em Ciência Política) - Faculdade de Filosofia, Letras e Ciências Humanas, Universidade de São Paulo, São Paulo, 1981.

MORAES, A. C. R. Geografia, interdisciplinaridade e metodologia. GEOUSP - Espaço e Tempo (Online), São Paulo, v. 18, n. 1, p. 9-39, 2014. 
Geografia histórica do Brasil: capitalismo, território e periferia. São Paulo: Annablume, 2011.

Geografia histórica do Brasil: cinco ensaios, uma proposta e uma crítica. São Paulo: Annablume, 2009.

Território e história no Brasil. São Paulo: Hucitec, 2002.

Geografia, capitalismo e meio ambiente. Tese (Livre-Docência em Geografia)

- Faculdade de Filosofia, Letras e Ciências Humanas, Universidade de São Paulo, São Paulo, 2000.

Notas sobre identidade nacional e institucionalização de geografia no Brasil. Estudos Históricos, Rio de Janeiro, v. 4, n. 8, p. 166-176, 1991.

Ideologias geográficas - espaço, cultura e política no Brasil. São Paulo: Hucitec, 1988.

NEWMAN, D. On Borders and Power: A Theoretical Framework. Journal of Borderland Studies, v. 18, n. 1, p. 13-24, 2003.

NOGUEIRA, C. E. A apropriação metodológica das frentes pioneiras na formação da Geografia Brasileira (1930-1950). Terra Brasilis (Nova Série), n. 5, 2015. Disponível em: http://journals.openedition.org/terrabrasilis/1480. Acesso em: 6 mar. 2018.

O lugar da fronteira na geografia de Pierre Monbeig. Tese (Doutorado em Geografia Humana) - Faculdade de Filosofia, Letras e Ciências Humanas, Universidade de São Paulo, São Paulo, 2013.

A conquista do Brasil central: fronteiras e frentes pioneiras no século XIX. Scripta Nova - Revista Electrónica de Geografía y Ciencias Sociales, Barcelona: Universidad de Barcelona, v. XVI, n. 418(9), 2012. Disponível em: http://www.ub.edu/ geocrit/sn/sn-418/sn-418-9.htm. Acesso em: 6 mar. 2018.

NOMURA, H. Centenário da Comissão Rondon (1907-2007): personagens, descobertas e produção bibliográfica. Cadernos de História da Ciência - Instituto Butantan, São Paulo, v. 5, n. 1, p. 79-105, jan./jul. 2010.

OLIVEIRA, L. M. L. Natureza e identidade: o caso brasileiro. Desigualdade E Diversidade - Revista de Ciências Sociais, Rio de Janeiro: PUC, n. 9, p. 123-134, ago./ dez. 2011.

Americanos: representações da identidade nacional no Brasil e nos EUA. Belo Horizonte: Ed. UFMG, 2000.

A questão nacional na Primeira República. São Paulo: Brasiliense, 1990.

ORTIZ, R. A sociologia de Pierre Bourdieu. São Paulo: Olho d'Água, 2003.

PEREIRA, S. L. N. Sociedade de Geografia do Rio de Janeiro: origens, obsessões e conflitos (1883-1944). Tese (Doutorado em Geografia Humana) - Faculdade de Filosofia, Letras e Ciências Humanas, Universidade de São Paulo, São Paulo, 2003. 
SÁ, D. M.; SÁ, M. R.; LIMA, N. T. Telégrafos e inventário do território no Brasil: as atividades científicas da Comissão Rondon (1907-1915). História, Ciências, Saúde - Manguinhos, Rio de Janeiro, v. 15, n. 3, p. 779-810, 2008.

RONDON, C. M. S. Missão Rondon: apontamentos sobre os trabalhos realizados pela Comissão de Linhas Telegráficas Estratégicas de Mato Grosso ao Amazonas, de 1907 a 1915. Brasília: Senado Federal/Conselho Editorial, 2003.

Conferências realizadas perante a Sociedade Rural Brasileira - São Paulo, 31 de julho de 1920; Cuiabá, 15 de dezembro de 1919; e Piracicaba, 4 de agosto de 1920. Rio de Janeiro: Typographia Leuzinger, 1922.

SACK, R. D. Human Territoriality: Its theory and history. London: Cambridge University Press, 1986.

SANTOS, M. A natureza do espaço: técnica e tempo, razão e emoção. São Paulo: Edusp, 2002.

Pensando o espaço do homem. São Paulo: Hucitec, 1997.

Metamorfoses do espaço habitado. São Paulo: Hucitec, 1988.

SCHWARTZMAN, S. Um espaço para a ciência: a formação da comunidade científica no Brasil. Brasilia, DF: MCT, 2001.

TAYLOR, P. The state as container: territoriality in the modern world-system. Progress in Human Geography, n. 18, p. 151-162, 1994.

VLACH, V. R. F. Estudo preliminar acerca dos geopolíticos militares brasileiros. Terra Brasilis, n. 4-5, 2003. Disponível em: http://journals.openedition.org/terrabrasilis/359. Acesso em: 6 mar. 2018.

WALLERSTEIN, I. Após o liberalismo. Petrópolis, RJ: Vozes, 2002.

ZUSMAN, P. B. Sociedades geográficas na promoção o saber a respeito do território: estratégias políticas e acadêmicas das instituições geográficas na Argentina (1879-1942) e no Brasil (1838-1945). Dissertação (Mestrado em Geografia Humana) -Faculdade de Filosofia, Letras e Ciências Humanas, Universidade de São Paulo, São Paulo, São Paulo, 1996. 